\title{
Approximate Truth, Quasi-Factivity, and Evidence
}

\section{Michael J. Shaffer}

\section{Acta Analytica}

International Periodical for Philosophy in the Analytical Tradition

ISSN 0353-5150

Volume 30

Number 3

Acta Anal (2015) 30:249-266

DOI 10.1007/s12136-014-0245-5

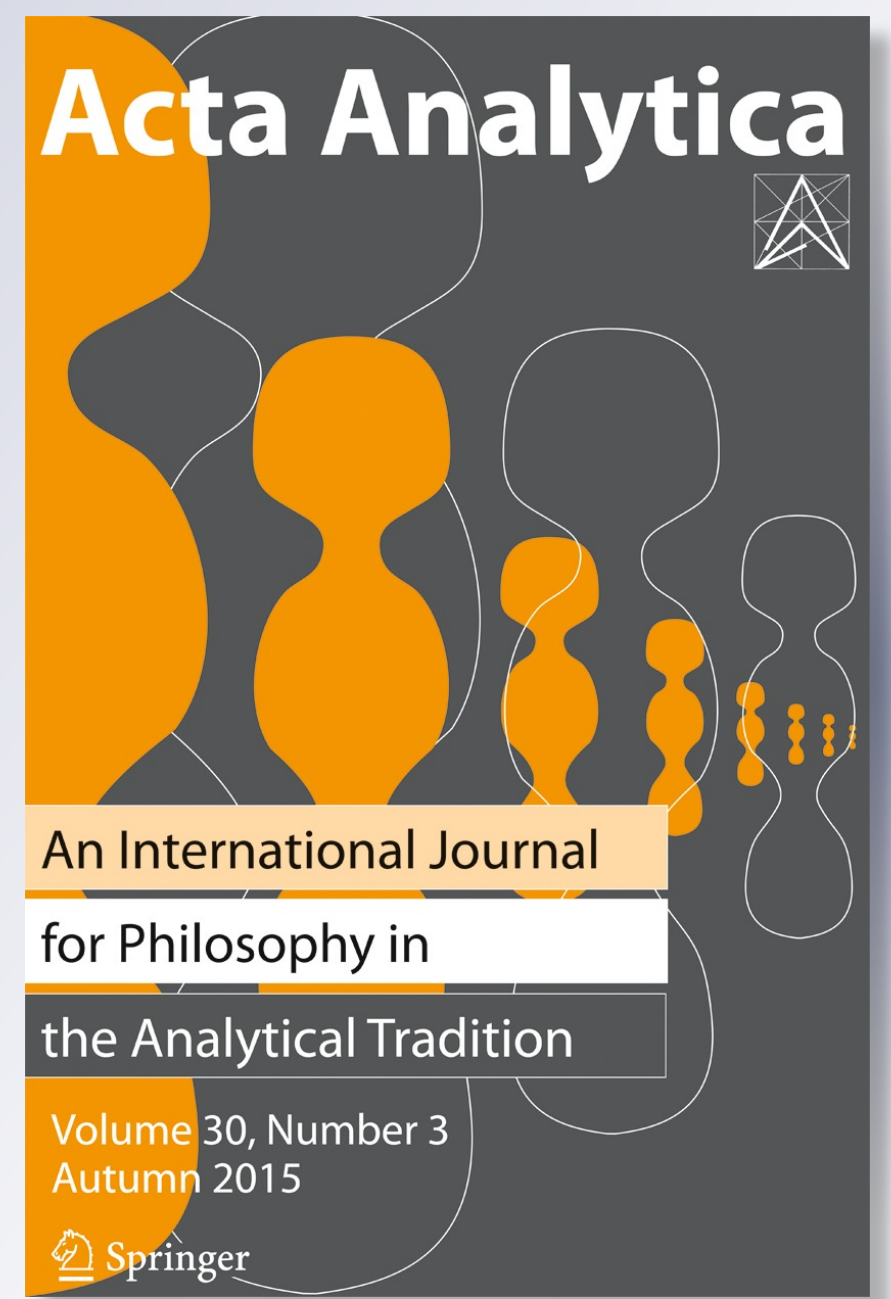

Springer 
Your article is protected by copyright and all rights are held exclusively by Springer Science +Business Media Dordrecht. This e-offprint is for personal use only and shall not be selfarchived in electronic repositories. If you wish to self-archive your article, please use the accepted manuscript version for posting on your own website. You may further deposit the accepted manuscript version in any repository, provided it is only made publicly available 12 months after official publication or later and provided acknowledgement is given to the original source of publication and a link is inserted to the published article on Springer's website. The link must be accompanied by the following text: "The final publication is available at link.springer.com". 


\title{
Approximate Truth, Quasi-Factivity, and Evidence
}

\author{
Michael J. Shaffer
}

Received: 6 January 2014 / Accepted: 11 April 2014 / Published online: 4 January 2015

(C) Springer Science+Business Media Dordrecht 2015

\begin{abstract}
The main question addressed in this paper is whether some false sentences can constitute evidence for the truth of other propositions. In this paper it is argued that there are good reasons to suspect that at least some false propositions can (at least some times) constitute evidence for the truth of certain other contingent propositions. The paper also introduces a novel condition concerning propositions that constitute evidence that explains a ubiquitous evidential practice and it contains a defense of a particular condition concerning the possession of evidence. The core position adopted here then is that false propositions that are approximately true reports of measurements can constitute evidence for the truth of other propositions. So, it will be argued that evidence is only quasi-factive in this very specific sense.
\end{abstract}

Keywords Evidence $\cdot$ Knowledge $\cdot$ Measurement . Factivity · Approximate truth

\section{Introduction}

The main question addressed in this paper is whether some false sentences can constitute evidence for the truth of other propositions. As we shall see, there are, in fact, some good reasons to suspect that at least some false propositions can (at least some times) constitute evidence for the truth of certain other contingent propositions. One major goal of this paper is to articulate these reasons. The argument presented in this paper extends and generalizes the results from Shaffer (2012a). The paper also introduces a novel condition concerning propositions that constitute evidence that explains a ubiquitous evidential practice and it contains a defense of a particular condition concerning the possession of evidence. The core position adopted here then is that false propositions that are approximately true reports of measurements can constitute evidence for the truth of other propositions. So, it will be argued that evidence is only quasi-factive in this very specific sense.

M. J. Shaffer $(\bowtie)$

Department of Philosophy, St. Cloud State University, CH365N 720 4th Ave. South, St. Cloud, MN 56301, USA

e-mail: mjshaffer@stcloudstate.edu 


\section{$2 \mathrm{E}=\mathrm{K}$ and the Factivity of Evidence}

In order to see where and how the problems to be discussed in this paper arise, it is instructive to take a closer look at the motivation behind the view that all evidence must be true. Recently, there has been some important discussion of the nature of evidence qua its truth/falsity and Littlejohn (2013) is an instructive introduction to this debate. Littlejohn (2013) is also a spirited defense of the view that evidence must be true, and it is a direct response to some arguments against that view given by Fantl and McGrath (2009) and Rizzieri (2011), among others. ${ }^{1}$ Littlejohn calls those who defend the thesis that evidence must be true "truthers" and he understands this view as follows:

(ET) $\mathrm{p}$ is evidence only if $\mathrm{p}$ is true. ${ }^{2}$

Littlejohn then recognizes that there are, in fact, two separate distinctions concerning the nature of evidence involved in the debate. As we have already seen, the first distinction concerns the truth/falsity of evidence. But, the second distinction concerns just what evidential states are. With respect to this second distinction, on the one hand, many epistemologists treat evidence as propositional. But, on the other hand, some epistemologists treat evidence as a type of psychological state. However, the difference of opinions on this latter matter is largely independent of the issue concerning the truth/ falsity of evidence. Here we will only be concerned with the propositional view and so the second distinction about the nature of evidence will simply be ignored for the purposes of this paper.

In any case the truther view of what constitutes specifically propositional evidence can be succinctly stated as follows:

(PET) $\mathrm{p}$ is propositional evidence only if $\mathrm{p}$ is true.

Littlejohn then calls those who reject ET "falsies," and in contrast to PET the propositional version of the falsie view is easily understood as follows:

(PEF) $\mathrm{p}$ can be propositional evidence even if $\mathrm{p}$ is false.

We can then turn to the matter of what considerations are supposed to support ET and PET against PEF. So, what are the main motivations behind the endorsement of the truther view?

First, the central consideration offered in support of the truther view is the contention that the propositions that constitute evidence e for some other proposition $\mathrm{p}$ are supposed also to constitute good reasons for $\mathrm{p}$ in virtue of their being evidence. But, according to the truthers, if $\mathrm{e}$ is false, then e cannot constitute good reasons for $\mathrm{p}^{3}$ This is supposed to be an obvious point and it is based on the deeper contention that if e is false, then it is not evidence at all. According to this view, one might reasonably take e

\footnotetext{
${ }^{1}$ See Bird (2004), Hyman (2006), Unger (1975), Fantl and McGrath (2009), Rizzieri (2011), and Schroeder (2011).

${ }^{2}$ Littlejohn (2013).

${ }^{3}$ See, for example, Littlejohn $(2011,2013)$ and Leite (2013).
} 
to be evidence for $\mathrm{p}$ if $\mathrm{e}$ is false, but truthers argue that there is an important distinction that we must draw between what is taken to be evidence and what is actually evidence.

Second, in endorsing his own particular version of the truther view, Williamson (2007, p. 209) has argued as follows: We are supposed to all agree that it is bad for any assertion to be inconsistent with the evidence. This is supposed to be the case because if an assertion is inconsistent with the evidence, then it is false. But, according to Williamson, this explanation of why it is bad for any assertion to be inconsistent with the evidence assumes that all evidence is true. Otherwise, we would have to accept that there are true propositions of the form " $\mathrm{e}$ is false" that are evidences (because $\mathrm{p}$ is false ex hypothesi) but where $\mathrm{e}$ is inconsistent with the evidence. ${ }^{4}$

Finally, Littlejohn (2011) has offered two additional arguments in support of the truther view. Littlejohn's first argument appeals to linguistic factors and his second argument appeals to explanatory factors. ${ }^{5}$ Littlejohn's linguistic argument essentially appeals to linguistic intuitions concerning assertions of propositions that are supposed to serve as evidence. The kinds of cases he has in mind that are alleged to support the truther view involve an agent asserting a proposition e as evidence for some proposition $\mathrm{p}$ in contexts where it is also contextually acknowledged that $\mathrm{e}$ is false. The implication is then that such assertions are defective. Specifically, these defective assertions involve asserting that "e is evidence for $\mathrm{p}$, but $\neg \mathrm{e}$ " and Littlejohn claims that the only way to credibly explain what is wrong with such defective assertions is to adopt the truther view. Littlejohn's second argument concerns the role that evidence plays in explanatory inference and it is based on the contention that when we have some evidence e and we find that the best explanation of that evidence is $\mathrm{p}$, we know that $\mathrm{e}$ is the case because of p. ${ }^{6}$ Littlejohn then claims that the explanation of this sort is factive both with respect to the explanans and the explanandum positions in proposition with the form "e because p." From this it follows if $\mathrm{e}$ is evidence, then either e is a brute fact or e is a fact explained by some $\mathrm{p}$. In both cases, it turns out that if e is evidence, then it is true.

We shall return to these arguments subsequently, but it is worth looking in a bit more detail at the truther view itself. The most well-known locus of the defense of ET in general, and PET in particular, is Timothy Williamson's recent work in epistemology and this will help to illustrate the main features of evidence that are at issue in this debate by unpacking that view. As part of his radical knowledge-first epistemology Williamson (2000) has famously argued that one's evidence is equivalent to what one knows. This thesis has come to be widely known as the " $\mathrm{E}=\mathrm{K}$ " thesis, and it is a central element of his general epistemological views. Let " $\mathrm{K}_{\mathrm{S}} \mathrm{p}$ " signify that $\mathrm{S}$ knows that $\mathrm{p}$ and " $E_{S} p$ " signify that $\mathrm{p}$ is evidence for $\mathrm{S}$. This thesis can then be captured simply and clearly as follows:

$$
(W 1)(\forall S)(\forall p) \mathrm{Esp}=\mathrm{Ksp}
$$

Another crucially important component of Willimason's view of knowledge is the view that knowledge is the most general factive mental state operator. According to this

\footnotetext{
${ }^{4}$ See also Williamson (2009, p. 310).

${ }^{5}$ Littlejohn (2011, pp. 252-254).

${ }^{6}$ Littlejohn (2011, pp. 254-255).
} 
view, if a proposition is known, then it is true. This is just the familiar and orthodox sort of factivity condition for knowledge and it can be simply stated as follows:

$$
(W 2)(\forall S)(\forall p) \mathrm{Ksp} \rightarrow p
$$

What W1 and W2 directly and perhaps surprisingly entail is the following very interesting and not so obviously true claim:

$$
(W 3)(\forall S)(\forall p) \mathrm{Esp} \rightarrow p
$$

What W1 and W2 entail is a factivity condition for evidence. ${ }^{7}$ The problem that will be addressed here is that W3 is clearly false and this can be seen from examining cases from both the sciences and from our more mundane epistemic life. In particular, this can be seen from looking at evidential practice as it pertains to measurement. ${ }^{8}$ Let us then turn to the examination of these sorts of cases that are alleged to show that W3 is false.

\section{The Argument from Approximation and the Epistemic Role of Measurement}

Millikan's famous oil drop experiments were conducted in order to empirically determine the charge on an electron, e, and to determine that electrical charge was quantized in discreet units rather than continuous. ${ }^{9}$ So, let us then consider the manner in which this experiment was performed in order to confirm the claim that electrical charge is quantized. To begin, the value of e is theoretically determined as follows. Where $N_{A}$ is Avogadro's constant and $F$ is Faraday's constant, the value of $e$ is given by the equation $e=F / N_{A}$. But, Millikan's experimental procedure to empirically determine the value of $e$ was quite complex and involved spraying small electrically charged drops of oil in an electric field produced in an ingenious apparatus. This apparatus involved a parallel pair of horizontal metal plates across which a uniform electrical field was created. The oil drops were allowed to fall and then rise due to the effect of the electrical field produced in Millikan's apparatus. These droplets move at a rate determined by gravity, the viscosity of the air, and the electric force involved. The gravitational and viscous forces on the oil drops are calculated based on the size and velocity of the oil drops. As a result, the electric force on the oil drops can thereby be determined. Since this electric force is the product of the electric charge and the electric field involved, the electric charge of the oil drops can also be determined. By measuring the electrical charges of many oil drops, Millikan was able to determine both the value of $e$ and that the charges are all integer multiples of e (i.e., that they are quantized). Determining a relatively exact value of $e$ involved measuring the following parameters involved in the experiments using his apparatus as accurately as possible: temperature, pressure, voltage, the coefficient of viscosity of air, the density of clock oil, the value of the gravitational constant, and the times of rise and fall of the oil drops. The important point to note here is that all of Millikan's measurements were - and still do - constitute evidence for the claim that electrical charge is quantized. But, the measured quantities used to indirectly determine the value of $e$ are all approximations. This is due to the measurement errors

\footnotetext{
${ }^{7}$ See Littlejohn (2013) on truth and evidence.

${ }^{8}$ See Hilpinen (1988) for a related idea.

${ }^{9}$ See Franklin (1997).
} 
inherent in determining the values of the relevant parameters in the experiment. More accurate and contemporary experimental methods have determined that the value of $e$ is $1.602176487(40) \times 10^{-19} \mathrm{C}$. But, Millikan's experiment determined the value of $e$ to be $1.5924(17) \times 10^{-19} \mathrm{C}$ on the basis of sets of measurements generated by a significant number of experimental runs. So, the evidence that confirms the claim that electric charge is quantized is only approximately true and this is due to the inexactness of the various methods of measurement used in the oil drop experiment. So, it would appear to be the case that some propositions can be evidence even though they are only approximately true. This further entails that at least some false propositions can constitute evidence.

A more mundane example of this aspect of evidential practice and its methodological significance can be seen in the following admittedly hypothetical but perfectly ordinary case. Suppose that Jane is attempting to move her couch into her new apartment. So, let us suppose that she measures the width of the couch and the width of the entry door to her apartment using a standard tape measure. Suppose that she determines via this method that the door is $3.5 \mathrm{ft}$ wide and that the couch is $4.5 \mathrm{ft}$ wide. ${ }^{10}$ On this basis, she might reasonably conclude that the couch will not fit through the doorway. Suppose also, however, that due to the inexactness of Jane's measurements, the door is not exactly $3.5 \mathrm{ft}$ wide. Suppose that it is really $3.51246 \mathrm{ft}$ wide. Suppose also that the couch is not exactly $4.5 \mathrm{ft}$ wide and that it is really $4.489 \mathrm{ft}$ wide. As in our scientific case, it should be clear that Jane's measured figures are false but approximately true. However, as in the case of Millikan's oil drop experiment, those pieces of evidence are, nevertheless, still very good evidence for the claim that the couch will not fit through the doorway. So, as in the case of Millikan's experiment, it would appear to be the case that some propositions can be evidence even though they are only approximately true. Again, this further entails that at least some false propositions can constitute evidence.

One might be tempted to respond that all scientific measurements are understood to have implicit error bars representing their uncertainty as follows: $x \pm \delta$. Thus, they are not just approximately true. The propositions that are reports of such measurement results would then be the true ranges of values. However, this does not undermine the fact that the claim that the value of $e$ is $1.5924(17) \times 10^{-19} \mathrm{C} \pm \delta_{1}$ is only approximately true relative to the more accurate value of $1.602176487(40) \times 10^{-19} \mathrm{C} \pm \delta_{2}$. The ranges of such measures need not coincide at all. ${ }^{11}$ Moreover, this is clearly not true of everyday measurements such as using a tape measure to see if a couch will fit through a door. No error bars are involved at all in such cases and so this response ultimately does nothing to undermine the conclusion that at least some false but approximately true propositions can constitute evidence.

It should be clear then that these sorts of examples are absolutely commonplace both in the sciences and in everyday life, and they exemplify the following crucial and very general insight. It appears to be the case that in most (if not all) real cases, the measurement evidence that confirms and disconfirms hypotheses is not - strictly speaking - true. The kinds of measured values that often constitute evidence in the

\footnotetext{
${ }^{10}$ Let us also assume that this dimension of the couch is such that the couch cannot be manipulated so as to reduce the width of the couch relative to the width of the door. So, for example, it cannot be tilted.

${ }^{11}$ They may do so, but they need not do so in order to constitute evidence.
} 
sciences and everyday life are typically only approximately true because they are inexact by their very nature. But, all approximately true claims are false. ${ }^{12}$ Adopting Williamson's or Littlejohn's truther view would then appear to commit us to the totally implausible view that the measurements made in such cases are not really evidence at all, because they are not true, and that the hypotheses that such measurements appear to support are not, in fact, confirmed on the basis of those measurements. This would effectively eliminate the possibility that measured values ever constitute evidence in the conduct of the science and in our more mundane epistemic lives. So, adopting the truther view of evidence with respect to propositions that report measurements undermines the very possibility of conducting rational empirical inquiry involving measurement. But, this is clearly at odds with actual practice and such measurements are evidence in both the sciences and everyday life, often exceptionally good evidence.

Let us call this general critical observation the argument from approximation. It will be understood here as follows:

P1: Measurements are inexact.

$\mathrm{P} 2$ : If measurements are inexact, then the propositions that are reports of the results of measurements are at best approximately true.

P3: The propositions that are reports of the results of measurements often constitute evidence.

P4: If the propositions that are reports of the results of measurements are at best approximately true and the propositions that are reports of the result of measurements often constitute evidence, then propositions that often constitute evidence are false.

Therefore, propositions that often constitute evidence are false.

This argument is compelling in light of the examples presented above and its scope is really quite broad given the evidentiary role that measurement plays in the sciences and in everyday epistemic practice. We can see this ubiquity in virtue of the two utterly commonplace and representative cases just discussed. They are essentially no different than a myriad of similar examples that could be cited in support of this aspect of evidential practice. So, at least in normal practice, evidence is not factive and W3 appears to be false. It follows then that W1, W2, or both W1 and W2 are false and that either one of or both of these cornerstones of Williamson's knowledge-first epistemology must be conceded if the facts of confirmational practice are respected. Other truthers face the same sort of problem and to deny this result would amount to a commitment to the implausible claims both that actual cases of measurement never (or at least only very rarely) have evidentiary significance and that most claims for which we purportedly have evidence in the form of measurements are not, in fact, supported by evidence at all. Moreover, given that the factivity condition on knowledge is such a deeply held orthodoxy in epistemology, it appears to be the case that it is much more reasonable to suppose that $\mathrm{W} 1$ must be ceded in the face of the relevant and important aspects of confirmational practice. This, it seems to be the case both that $\mathrm{E} \neq \mathrm{K}$ and that PET is false. However, if $\mathrm{E} \neq \mathrm{K}$ and PET is false we are faced with deeply interesting but vexing questions concerning what exactly can constitute evidence. Specifically, we

$\overline{{ }^{12} \text { See Hilpinen (1976), Kuipers }}$ (1978), Oddie (1986, 2008). 
need to determine under what conditions false propositions can at least potentially constitute evidence. Nevertheless, what this argument and the examples that support it show generally is that PET is false and that evidential practice supports PEF.

\section{At Least Some Evidence Is False and Approximately True}

The crucial question then to examine in light of the argument from approximation and the examples that support it is whether PEF is an acceptable and informative account of what really constitutes evidence. The contention made here is that, at least as stated, it is neither completely acceptable nor sufficiently informative as an account of what constitutes evidence. This is because it is too broad. Simply put, PEF does not identify specifically what feature of the propositions reporting measurements in those cases accounts for their constituting evidence. So, while the examples and the argument from approximation constitute good reasons to reject PET, they do not support an unrestricted form of PEF, because PEF lacks an important degree of specificity concerning the important feature that the measurement examples turn on. Specifically, in our examples the propositions that constitute evidence are not just any old false propositions. The propositions that constitute evidence in the examples detailed above constitute evidence not in virtue of their bare falsity, but rather in virtue of their being false but approximately true. So, while PEF is broadly correct because all approximately true propositions are false, it does not reveal what it is about the false propositions in question that allows for them to constitute evidence. As a result, while the falsie view defended here is in agreement with PEF, it is much more specific and informative. The contention here then is that PEF should be replaced with the following quasi-factive constitutional condition on evidence:

(PEAT) $\mathrm{p}$ is propositional evidence only if $\mathrm{p}$ is at least approximately true.

Here a proposition's being at least approximately true indicates that it is true or approximately true. ${ }^{13}$ The adoption of PEAT then clearly constitutes a substantial rejection of PET but does not commit one to the prima facie implausible view that just any false proposition can constitute evidence.

\subsection{The Nature and Possession of Evidence}

So, given PEAT and the rejection of both PEF and PET, there is still more that can be said about both the constitution and possession of evidence. These topics can be approached usefully via the consideration of the most commonplace argument against PET raised by several defenders of PEF. This type of argument begins with the specification of a case where an agent has a justified belief in a proposition $p$ that is not a case of knowledge. In these sorts of cases, the agent has (subjective) reasons that are supposed to be well-supported enough to qualify as justified beliefs, but those reasons may be false. So, the cases involve justified beliefs that are alleged to be evidence even though they are not known and may be false. On this sort of basis, these

\footnotetext{
${ }^{13}$ Compare Shaffer (2012b) and Shaffer (2012c) on this idea in the context of the norms of practical reasoning and the norms of assertion.
} 
defenders of the PEF then endorse the following general principle about the possession of evidence:

(JBE) if an agent $\mathrm{x}$ is justified in believing a proposition $\mathrm{p}$, then $\mathrm{p}$ is a part of $\mathrm{x}$ 's stock of evidence.

So, from the relevant cases and JBE, these defenders of PEF draw the conclusions that both W1 and PET are false. Let us call this argument the canonical falsie argument, and it is clear that it is supposed to show both that evidence is not equivalent to knowledge and that false propositions can be evidence.

As we have already seen, the view defended here, however, constitutes a rejection of both the truther and falsie views. So, the view of evidence presupposed here and the rejection of PET that is grounded in the argument from approximation is not merely a variation on the thematic idea captured in the canonical falsie argument. The falsies who appeal to the canonical falsie argument couple PEF with the account of evidence possession articulated in JBE. So, they believe that one's evidence is equivalent to what one justifiably believes - rather than what one knows - and they believe that false propositions can constitute evidence. With respect to the issue of what is required for one to possess evidence, truthers like Williamson and Littlejohn disagree and hold that possessing evidence requires knowledge. More specifically, Williamson holds that possessing evidence requires having knowledge simpliciter while Littlejohn holds that possessing evidence requires having non-inferential knowledge. ${ }^{14}$ So, respectively, they endorse the following possession conditions for evidence:

(KE) if an agent $\mathrm{x}$ knows a proposition $\mathrm{p}$, then $\mathrm{p}$ is a part of $\mathrm{x}$ 's stock of evidence. (NIKE) if an agent $x$ non-inferentially knows a proposition $p$, then $p$ is a part of $x$ 's stock of evidence.

Truthers then couple such accounts of the possession of evidence with PET. Notice that particularly in the case of Williamson's view, the possession condition mirrors the constitution condition and so it is only when we consider the alternative does it become clear that the possession and constitution conditions can be decoupled.

In any case, the alternative view of the constitution of evidence defended here is based on PEAT, but the full view of evidence that is implied by the argument from approximation needs to be fleshed out further by articulating a more robust notion of the possession condition for such evidence. However, it is not immediately clear whether one who endorses PEAT ought to opt for JBE, KE, NIKE, or some different principles when it comes to the issue of the possession of evidence. In both the Millikan example and the more mundane couch example, the agents' possess propositional evidence for a certain proposition, but the evidence that they appeal to is false but approximately true. Nevertheless, in accordance with our views of ordinary evidential practice, they appear to have good reasons for the beliefs that they hold in these cases based on those approximately true evidential propositions. So, these cases militate against both the constitutional view that all evidence is true and the constitutional view that strictly false propositions can be evidence respectively. But, it is not quite as clear

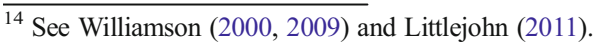


what they imply about the possession of evidence. Here the following possession condition will be adopted:

(JBATE) if an agent $\mathrm{x}$ is justified in believing that a proposition $\mathrm{p}$ is true or $\mathrm{x}$ is justified in believing that a proposition $\mathrm{p}$ is approximately true, then $\mathrm{p}$ is part of $\mathrm{x}$ 's stock of evidence.

JBATE is a natural accompaniment to PEAT and it entails that one can possess evidence when one is justified in believing that a proposition is strictly true or when one is justified in believing that a proposition is approximately true. It essentially asserts that one's stock of evidence is the set of propositions that one is at least justified in believing to be approximately true. So, given this view, in both the Millikan case and the couch case, the respective agents possess bona fide evidence. In both cases the agent so described is justified in believing that the relevant evidential proposition in that case to be true, even though those propositions are actually false and approximately true. The propositions in question that they believe constitute real evidence in terms of PEAT and, in accordance with JBATE, the agents possess that evidence in virtue of their justified beliefs in the relevant evidential propositions. So, in both cases we have false but approximately true propositions serving as bona fide evidence. The truther, however, cannot accommodate this result and, in virtue of this failing, truthers are committed to the utterly implausible position that in most actual cases where measurements are taken to be evidence, what we have are cases of appeals to propositions that do not really constitute evidence at all. So, according to the truther view, most of our actual scientifically generated beliefs (and many more of our more mundane beliefs involving measurement) are not evidentially grounded at all.

\subsection{Two Anticipated Truther Objections}

Truthers might immediately respond to the argument from approximation and the PEAT and JBATE versions of the falsie view by suggesting that in both the Millikan and couch cases, the agents in question are fully justified in believing that the relevant measurements are approximately true and so they both know a proposition of the form " $p$ is approximately true." Thereby, truthers might seek to salvage their view and avoid the negative implications of the argument from measurement by tweaking the cases so that they involve only true propositions that are known and so that they meet the truthers' constitution and possession conditions. This sort of response is closely related to the worry about error bars discussed earlier in the context of the Millikan case, and it is a strategic move that has been employed against views like PEAT and JBATE in the context of debates both about the norm of assertion and the norm of belief. ${ }^{15}$ But, it is no more effective in this context than it is in those cases.

This is simply because the agents in these cases do not even have any beliefs of that form at all and yet they still appear to possess what is perfectly good evidence. Jane may well outright and without qualification believe that the door is $3.5 \mathrm{ft}$ wide and that the couch is $4.5 \mathrm{ft}$ wide and so has evidence that the couch will not fit through the door.

\footnotetext{
${ }^{15}$ See Shaffer (2012b, c).
} 
In this case this expected truther response fails because she has good evidence but she cannot know that it is true that it is approximately true that the door is $3.5 \mathrm{ft}$ wide and that it is true that it is approximately true that the couch is $4.5 \mathrm{ft}$ wide when (ex hypothesi) she does not believe either the proposition that it is approximately true that the door is $3.5 \mathrm{ft}$ wide or the proposition that it is approximately true that the couch is $4.5 \mathrm{ft}$ wide. There is nothing unusual about such a case at all and the same goes for the Millikan case. Particularly reflective people, scientists included, might have such hyperintellectualized beliefs about approximate measurements of the form "it is true that $\mathrm{e}$ is approximately true," but it is certainly not typically the case and it does not seem to be the case that one must have such beliefs when dealing with measurements in order for the propositions that are reports of such measurements to constitute bona fide evidence. In fact, to reject this position on the nature and possession of evidence would be to concede the facts of evidential practice and to concede the plausible view that most actual evidential appeals to measurements are bona fide cases of justification generating appeals to evidence. The latter point should be especially compelling for obvious reasons and which have been emphasized here already.

The second easily anticipated objection to the view developed here concerns the perception that JBATE is "ugly" in some damaging respect, but this is not an especially serious challenge and so we can dispense with it quickly. Specifically, one might object that JBATE is "unnatural," "aesthetically monstrous," and/or ad hoc due to the perceived complexity and/or awkwardness of that principle relative to $\mathrm{KE}$ and/or NIKE. Recall that JBATE is stated as follows:

(JBATE) if an agent $\mathrm{x}$ is justified in believing that a proposition $\mathrm{p}$ is true or $\mathrm{x}$ is justified in believing that a proposition $\mathrm{p}$ is approximately true, then $\mathrm{p}$ is part of $\mathrm{x}$ 's stock of evidence.

Now, even if JBATE is not as natural sounding nor aesthetically pleasing as either KE or NIKE, that is no real worry. Such aesthetic arguments are not compelling. JBATE does involve a disjunctive antecedent and, more importantly, on this basis one might suspect that it has been artificially constructed in an ad hoc manner so as to curtail certain problems perceived to afflict its competitors. ${ }^{16}$ This is a more substantial worry, but ultimately it is not a serious worry either. This is because, unlike its competitors, JBATE captures ordinary and good evidential practice of the sort involved in measurement. So it is not an ad hoc construction and if capturing practice requires the appearance of unnaturalness and a little ugliness so what? Fidelity trumps beauty.

\subsection{Addressing the Truther Arguments}

Given the view defended here, what then can be said about the arguments introduced earlier that are supposed to favor the truther view? Recall that these arguments involved considerations related to the nature of good reasons, consistency, assertion and explanation, and the allegation was that only truther views provide the sort of account of evidence that can cope with these considerations. So, let us first return to the issue of

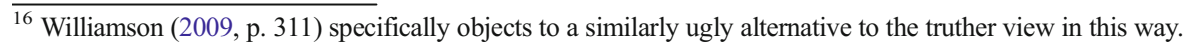


the relationship between evidence and good reasons. According to the view developed here, not all evidence is true, but no strictly false proposition constitutes evidence. According to the appeal to the nature of good reasons, propositions that are evidence are supposed to constitute good reasons. But, truthers claim that no false proposition can constitute a good reason. We can diffuse this argument by noting that, according to the view defended here, good reasons can sometimes be approximately true and that this is consonant with good evidential practice. In fact, as noted earlier, rejecting this possibility would imply accepting that most scientific propositions and many of the more mundane propositions that we believe to be justified are in fact unjustified because the measurements used as evidence for them are not strictly true. So, it seems to be far more realistic and reasonable to adopt the view that evidence can be true or false but approximately true.

Let us next turn our attention to Williamson's $(2007,2009)$ argument from inconsistency. Recall that his point was that it is bad for any assertion to be inconsistent with evidence. This claim is supposed to be true because of the following principle:

(WP) if an assertion is inconsistent with the evidence, then it is false.

Call this principle Williamson's principle and Williamson (2007, p. 209) claims that this explanation of why it is bad for any assertion to be inconsistent with the evidence assumes that all evidence is true. In other words, if we accept WP, then we are supposed to be committed to the truther view of evidence. So, he argues that if we reject the truther view evidence, then we must accept that there are some true propositions that are evidences of the form e is false that are inconsistent with the body of evidence and that we cannot properly explain why it is bad for a proposition to be inconsistent with the evidence.

This argument can be answered in the following way. First, it is not at all clear that it is always bad for any assertion to be inconsistent with the evidence. But, let us assume that this claim is true for the purposes at hand. What is more important here is that we ought to reject the claim that the best explanation of the claim that it is bad for any assertion to be inconsistent with the evidence is WP. Thereby, one can reject the assumption that all evidence is true. One can accept that the best explanation of the claim that it is bad for an assertion to be inconsistent with the evidence is WP when we are considering strictly true evidential propositions without accepting that all evidential propositions are strictly true. WP is only the best explanation of why it is wrong for some assertions to be inconsistent with the evidence. When we recognize that we must include evidential propositions that are approximately true in the body of evidence, it is no longer the case that WP is the best explanation of the wrongness of claims' being inconsistent with the evidence. Given the view here and the fact that it conforms to good evidential practice, the body of what ought to be treated as evidence includes some false but approximately true propositions in addition to strictly true evidential propositions. So, if we reject this argument for the truther view, it looks like we are obliged to explain more generally why it is bad for assertions to be inconsistent with approximately true evidential propositions and why it is bad for assertions to be inconsistent with strictly true evidential propositions. The natural suggestion for such a principle is that if an assertion is not consistent with the evidence, then it is not even approximately true. This principle does not assume that all evidence is true. It assumes 
only that evidence is either true or approximately true, it has a wider scope than WP, and it is a much better explanation of evidential practice than WP is.

Let us then turn our attention to Littlejohn's arguments for the truther view. First, let us consider the argument based on the nature of non-defective assertions. On this front Littlejohn argues that in ordinary cases the falsie view gets important linguistic facts about appeals to evidence wrong. Let us begin by considering the cases he appeals to involving Scarlet and Green (Littlejohn 2011, p. 252):

(SG1) Scarlet: Does the prosecution have solid evidence against Mustard? Green: The prosecution thinks it does. Here's the evidence they have: that he was the last one to see the victim alive, that he lied about his whereabouts on the night of the crime, that his fingerprints were on the murder weapon, and that we wrote a letter concerning details the police think only the killer could have known. Of course, Mustard wasn't the last person to see him alive, he didn't lie about his whereabouts, and his fingerprints weren't on the murder weapon.

(SG2) Scarlet: Does the prosecution have solid evidence against Mustard? Green: People seem to think they do. Here's the evidence they have: that he was the last one to see the victim alive, that he lied about his whereabouts on the night of the crime, that his fingerprints were on the murder weapon, and that we wrote a letter concerning details the police think only the killer could have known. That being said, I don't know if he's the last who saw the victim alive, I don't know if he lied, I don't know if his fingerprints weren't on the murder weapon and I don't know if he wrote a letter containing any details about the crime.

According to Littlejohn, if we accept PET then we can easily explain why it seems that Green contradicts himself in SG1. According to PET, it seems to be the case that Green contradicts himself in SG1 because Green contradicts himself in SG1. Evidence is factive and so it is contradictory to assert propositions of the form " $p$ is part of the prosecution's evidence, but $\neg$ p." With respect to SG2, the defender of PET can also explain what is going on. Given this view, Green's remarks in SG2 only seem to be contradictory. They involve the appearance of contradiction in the same manner that more familiar Moorean assertions of the form " $p$, but I do not believe that p" do.

The alternative explanation of SG1 and SG2 that involves the acceptance of PEF is then supposed to be problematic because if the defender of PEF tries to undermine the evidence that Littlejohn alleges SG1 provides for PET by claiming that Green's remarks only seems to be contradictory in SG1 (due to their Moore-like nature), then the argument for PET cannot be blocked because according to the PEF view, Green's remarks in SG2 should not seem to be contradictory. They seem to be contradictory only if PET is true. Littlejohn clarifies his point by looking at the following set of assertables:

(S1) p, but I do not believe p.

(S2) Although $\neg$ p, the prosecution is justified in believing $p$.

(S3) $\mathrm{p}$ is part of the prosecution's evidence, but $\neg \mathrm{p}$.

(S4) $\mathrm{p}$ is part of the prosecution's evidence, but I don't believe $\mathrm{p}$.

Essentially, what he is arguing for in response to the SG cases is that if one rejects PET, then the respective felicity/infelicity of S1-S4 cannot be explained. Since SG1 
and SG2 involve assertions like these, those who reject PET supposedly cannot adequately explain the alleged linguistic facts about SG1 and SG2.

To begin, notice that S1 is supposed to be infelicitous because in asserting S1 the speaker is professing a commitment to $\mathrm{p}$ and then denying that very commitment in the same breath. However, propositions of that form can be true and so are not strictly contradictory. More importantly, Littlejohn claims that those who deny PET are (at least typically) committed to the equivalence of S2 and S3. This is supposed to be the case because most defenders of PEF hold that one's evidence is constituted by the propositional contents of some of one's non-factive mental states. It is clear though that one can be justified in believing falsehoods and so S2 is felicitous. But, then the defender of $\mathrm{PEF}$ is faced with the apparently daunting task of explaining why S2 is felicitous and $\mathrm{S} 3$ is infelicitous while maintaining that evidence can be false. Moreover, the defenders of PEF are supposed to be committed to the view that S3 and S4 only seem to be contradictory in the same way that $\mathrm{S} 1$ is supposed only to seem to be contradictory. But that entails that the S1-style explanation of seeming contradictoriness of S3 is that the assertion involved in S3 involves professing a commitment to the truth of evidence that is then denied. But that explanation assumes PET. Similarly, offering an S1-style explanation of the seeming contradictoriness of S4 also assumes PET for the same reasons. So, defenders of PEF cannot supposedly explain the infelicity of S1, S3, and S4 and the felicity of S2 in an adequate manner if they continue to maintain that evidence can be false. In other words, the only adequate explanation of the infelicity of $\mathrm{S} 1, \mathrm{~S} 3$, and S4 and the felicity of S2 is PET. So, what can the defender of PEAT say in response to this?

Let us begin by recalling that the defender of PEAT holds that evidence is only quasi-factive and so can be constituted by propositions that are strictly true and by propositions that are false but approximately true, whereas the defender of PEF holds that evidence can be constituted by false propositions. The defenders of PET hold that only true propositions can constitute evidence. In virtue of these differences, PEAT turns out to be superior to both PEF and PET as an explanation of linguistic practice. This can be seen as follows. First, we should recognize that not all sentences with the $\mathrm{S} 1$ form are infelicitous, as is argued in Shaffer (2012c). Specifically, we can see that it is sometimes felicitous to assert propositions of the form " $p$, but I do not believe p" when $\mathrm{p}$ is approximately true and the asserter is justified in believing that $\mathrm{p}$ is at least approximately true.

Since this linguistic fact is an important element in the response to Littlejohn's linguistic argument, let us look more closely at the case for the felicity of at least some Moorean sentences. To begin, consider the following case from Shaffer (2012c):

(MATH1) Joe is an elementary school mathematics teacher and he is teaching his students about geometry. In the course of teaching, his students how to calculate the area of a circle via the use of the equation $A=\pi r^{2}$, he tells his students the value of $\pi$. Specifically, he says that $\pi=3.14159$.

Joe works out several examples and the students learn how to do this for themselves and MATH1 seems to be an utterly pedestrian and realistic case. There is nothing at all odd or unusual about it and such actual cases of precisely this sort are commonplace. However, in MATH1 Joe asserts that $\pi=3.14159$ via his uttering the English sentence 
"the value of pi is 3.14159." But, strictly speaking, this is not true. However, it is close enough for the purposes of Joe and his students. But, according to defenders of the knowledge norm of assertion (i.e., that one should only ever assert propositions that are known and hence true), Joe is violating the proper norm of assertion. ${ }^{17}$ So, his assertion is defective in virtue of that view. However, this is not at all plausible. Joe is asserting a proposition in a perfectly ordinary sense and his assertion seems entirely appropriate in the context in which he is making that assertion. He is making an assertion that involves a not-exactly-true or approximately true proposition, and this seems entirely reasonable in the case as it is described. So, there is clearly something wrong with the knowledge norm of assertion, but it is not simply a case where one can reasonably bite the bullet and claim that Joe's behavior is epistemically irrational, as might be the case if he were baldly asserting a falsehood that was not approximately true. As such, it seems to be the case that it can be epistemically rational to assert some falsehoods when they are approximately true.

Let us then consider the following slight modification of MATH1 also from Shaffer (2012c):

(MATH2) Joe is an elementary school mathematics teacher and he is teaching his students about geometry. In the course of teaching his students how to calculate the area of a circle via the use of the equation $A=\pi r^{2}$, he tells his students the value of $\pi$. Specifically, he says that $\pi=3.14159$. Joe works out several examples and the students learn how to do this for themselves. After class he winks at his best student Jane, who is aware that his assertion about the value of pi is only an approximation, and says "the value of pi is 3.14159 , but I don't believe it."

The Moorean proposition in MATH2 has the supposed air of paradox about it that many have attributed to Moorean propositions, but this is only a prima facie problem given the idea that it can be perfectly rational to assert claims that are approximately true in addition to claims that are strictly true. If, as we have seen in MATH1, it is at least sometimes epistemically appropriate to assert approximately true propositions that one is at least justified in believing to be approximately true, then there is nothing wrong with Joe's assertion in MATH2. This can be seen more clearly as follows. In MATH2 Joe is asserting the following compound proposition:

(C) The value of pi is 3.14159 , but I don't believe it.

This involves the assertion of a compound proposition made up of the following two component propositions:

(CP1) The value of pi is 3.14159 .

(CP2) I do not believe that the value of pi is 3.14159 .

In attempting to assert C, Joe's assertion of CP1 might initially appear to grate against his assertion that $\mathrm{CP} 2$, but this dissonance vanishes when the assertion is understood in terms of the view of an account of the norm of assertion that sanctions

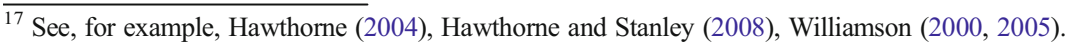


the assertion of some approximate truths. If $\mathrm{C}$ is properly asserted in virtue of such a norm, then both $\mathrm{CP} 1$ and $\mathrm{CP} 2$ are at least approximately true and it is at least the case that Joe is justified in believing that they are approximately true. In the case of CP1 this is because that proposition is approximately true and Joe is justified in believing that it is approximately true. In the case of $\mathrm{CP} 2$ this is because that proposition is true and he is justified in believing that it is true, so he does not really believe that the value of pi is, strictly speaking, 3.14159. So, the context of the assertion of CP1 in MATH2 renders that assertion epistemically rational, despite its involving an approximation, and this is fully compatible with the simultaneous epistemically rational assertion of CP2. In virtue of this observation, Joe is making a real and fully coherent assertion in asserting $\mathrm{C}$, despite its superficial paradoxical and infelicitous character.

Given this view, we can see that one can felicitously assert at least some propositions that are reports of measurements without also believing them to be strictly true. Consider the following cases:

(SG3) Scarlet: Does the prosecution have solid evidence that Mustard was speeding on highway 94 in the $65 \mathrm{mph}$ zone? Green: The prosecution thinks it does. Here's the evidence they have: Using a radar gun, officer Plum measured the speed of the car Mustard was driving to be $70 \mathrm{mph}$. Of course, Mustard wasn't driving 70 $\mathrm{mph}$.

(SG4) Scarlet: Does the prosecution have solid evidence that Mustard was speeding on highway 94 in the $65 \mathrm{mph}$ zone? Green: The prosecution thinks it does. Here's the evidence they have: Using a radar gun, officer Plum measured the speed of the car Mustard was driving to be $70 \mathrm{mph}$. That being said, I do not know that Mustard was driving $70 \mathrm{mph}$.

As in the MATH cases, the defender of the PEAT view is in a position to accept that Green's respective assertions in SG3 and SG4 are actually felicitous. Take the assertion being made in SG3, for example. It involves the assertion of the following compound proposition:

(G) The radar gun measurement of Mustard's car's speed being $70 \mathrm{mph}$ is part of the prosecution's evidence, but it is not the case that Mustard's car's speed was 70 mph.

This is a compound proposition that consists of the following component propositions:

(GP1) The radar gun measurement of Mustard's car's speed being $70 \mathrm{mph}$ is part of the prosecution's evidence.

(GP2) It is not the case that Mustard's car's speed was $70 \mathrm{mph}$.

As in the MATH cases, G is not contradictory and is it not infelicitous to simultaneously assert GP1 and GP2. One can felicitously assert that Mustard was driving 70 $\mathrm{mph}$ as evidence for the claim that he was speeding while also failing to believe (strictly speaking) that it is true that Mustard was driving $70 \mathrm{mph}$, say because he was actually driving $69.956 \mathrm{mph}$ and the radar gun is not perfectly accurate. So, some statements 
with the S1 and S3 forms are felicitous in this way, and the same kind of treatment can be given in the case of SG4 propositions involving such measurements as evidence. The defender of PEAT can explain these facts, whereas the defender of PET cannot do so. Such assertions only seem to be infelicitous given PEAT, but they are (at least sometimes) perfectly rational to assert.

What is then important to recognize then is that while Littlejohn's argument demonstrates the superiority of PET over PEF with respect to the felicity/infelicity of S1-S4 when dealing with assertions of propositions other than those that report measurements that are only at least approximately true, PET is inferior to PEAT with respect to the explanation of assertion of such reports. In cases involving such propositions, the defender of PEAT can meet all of Littlejohn's worries. With respect to propositions that are reports of measurements that are only at least approximately true, propositions with the S1, S3, and S4 forms can be felicitous, propositions with the $\mathrm{S} 2$ and $\mathrm{S} 3$ forms are properly seen to be equivalent, and the defender of PEAT can offer a uniform explanation of the felicity of propositions with forms S1-S4 for all cases (i.e., both those involving strictly true evidential propositions and merely approximately true evidential propositions). PET cannot be used to explain the measurement cases and it incorrectly implies that all propositions of forms S1, S3, and S4 are infelicitous. Notice too that PEAT has all of the resources of PET for explaining to the felicity/infelicity of S1-S4 when dealing with assertions of propositions other than those that report measurements that are only at least approximately true. This is, of course, due to the disjunctive nature of the PEAT view. In virtue of this fact, PEAT is superior to both PET and PEF when it comes to the explanation of the relevant linguistic facts.

Finally, let us consider Littlejohn's (2011) argument based on the alleged factivity of explanation. According to this argument, evidence plays a central role in explanatory arguments. In such arguments we obtain some evidence e and then via the ordinary procedure of inference to the best explanation, we judge that some explanation $\mathrm{T}$ is the best explanation of e. When this is accomplished, we are in a position to know a proposition of the form "e because T". Littlejohn's contention is that in such situations we are also in a position to know that both e and $\mathrm{T}$ are true. This latter contention is supposed to be the case because both the explanans and explanadum positions in explanatory statements are factive. ${ }^{18}$ Where we know e and e is a brute fact that needs no explanation we also supposedly know that e is true. So, when we know that e is an element in our body of evidence, we know that e and so it is true. According to the view defended here, however, bona fide evidence can be true or approximately true and so some evidence is false. But, if Littlejohn is correct and the explanation is factive in the sense just discussed, then all evidence is true and so much the worse for the view defended here. However, it is simply false that explanation is strictly factive in this way, and if it were we would be forced to accept that virtually no one has ever explained any measurement or confirmed any theory by inference to the best explanation on the basis of measurements.

This is easy to see. Suppose that the explanans and explanadum positions in propositions of the form e because $\mathrm{T}$ were factive and that we have a case where $\mathrm{e}$ is a proposition reporting a measurement that is merely approximately true. So, we obtain some measurement evidence e and then via the ordinary procedure of inference to the

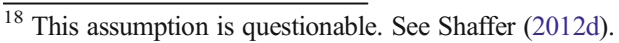


best explanation, we judge that some explanation $\mathrm{T}$ is the best explanation of e. According to Littlejohn, we would then be in a position to know a proposition of the form e because T. So, according to his reasoning, we would know that e is true. But, ex hypothesi e is false but approximately true. If one is inclined to maintain Littlejohn's explanatory argument for PET, then the only possible response to make to such cases is to reject the claim that $\mathrm{T}$ explains e in such cases. This is because, in virtue of their commitment to PET and the spirit of this argument, such truthers cannot reject the factivity of explanation and they cannot reject the claim that when T explains e then we are in a position to know a statement of the form e because T. So, if, as the defender of PET would have it, the e position in such statements is factive, then, in virtually all cases involving measurements, no explanation has been produced at all and so no theory has been confirmed. This is because the approximate truth of measurements that are taken to be evidence cannot in fact be evidence and cannot be explained in virtue of this. However, this would entail that in virtually every real case involving evidence that takes the form of a measurement report has not actually involved bona fide evidence. So, we have never explained much of anything ever, especially in the sciences. But, this is utterly implausible.

\section{Conclusion}

Against the truther view, it has been argued here that at least some, but not all, false propositions can be evidence. Specifically, it has been argued here at length that some approximately true propositions can be evidence. So, the view defended here is not that evidence is factive, but rather that evidence is quasi-factive. Yet more specifically, that the view defended here is that approximately true propositions that report measurements can, at least sometimes, constitute perfectly good evidence and when that view is coupled with the particular possession condition defended here, we get a full account of the nature and possession of evidence that is able to deal with the argument from approximation. Thus, unlike the truther view, it is consonant with an important and ubiquitous aspect of evidential practice. Finally, the view has also been shown to be immune to the kinds of objections that truthers have raised against those who hold that strictly false propositions can constitute evidence.

\section{References}

Bird, A. (2004). Is evidence non-inferential? The Philosophical Quarterly, 54, 252-256.

Fantl, J., \& McGrath, M. (2009). Knowledge in an uncertain world. Oxford: Oxford University Press.

Franklin, A. (1997). Millikan's oil-drop experiments. The Chemical Educator, 2, 1-14.

Hawthorne, J. (2004). Knowledge and lotteries. Oxford: Oxford University Press.

Hawthorne, J., \& Stanley, J. (2008). Knowledge and action. The Journal of Philosophy, 105, 571-590.

Hilpinen, R. (1976). Approximate truth and truthlikeness. In M. Przelecki, et al., Formal methods in the methodology of the empirical sciences (pp. 19-42). Dordrecht: D. Reidel.

Hilpinen, R. (1988). Knowledge and conditionals. Philosophical Perspective, 2, 157-180.

Hyman, J. (2006). Knowledge and evidence. Mind, 115, 891-916.

Kuipers, T. (1978). What is closer-to-the-truth? Amsterdam: Rodopi.

Leite, A. (2013). But that's not evidence; it's not even true! The Philosophical Quarterly, 63, 81-104.

Littlejohn, C. (2011). Evidence and knowledge. Erkenntnis, 74, 241-262. 
Littlejohn, C. (2013). No evidence is false. Acta Analytica, 28, 145-159.

Oddie, G. (1986). Likeness to truth. Dordrecht: D. Reidel.

Oddie, G. (2008). Truthlikeness. The Stanford encyclopedia of philosophy (fall 2008 edition), Edward N. Zalta (ed.). http://plato.stanford.edu/archives/fall2008/entries/truthlikeness/. Accessed 15 October 2014.

Rizzieri, A. (2011). Evidence does not equal knowledge. Philosophical Studies, 153, 235-242.

Schroeder, M. (2011). What does it take to have a reason? In A. Reisner \& A. Steglicj-Petersen (Eds.), Reasons for belief (pp. 201-222). Cambridge: Cambridge University Press.

Shaffer, M. (2012a). E does not equal K. The Reasoner, 7, 30-31.

Shaffer, M. (2012b). Not-exact-truths, pragmatic encroachment and the epistemic norm of practical reasoning. Logos \& Episteme, 3, 239-259.

Shaffer, M. (2012c). Moorean sentences and the norm of assertion. Logos \& Episteme, 3, 653-658.

Shaffer, M. (2012d). Counterfactuals and scientific realism. New York: Palgrave-MacMillan.

Unger, P. (1975). Ignorance. Oxford: Oxford University Press.

Williamson, T. (2000). Knowledge and its limits. Oxford: Oxford University Press.

Williamson, T. (2005). Contextualism, subject-sensitive invariantism and knowledge of knowledge. The Philosophical Quarterly, 55, 213-235.

Williamson, T. (2007). The philosophy of philosophy. London: Blackwell.

Williamson, T. (2009). Replies to critics. In P. Greenough \& D. Pritchard (Eds.), Williamson on knowledge (pp. 279-385). New York: Oxford University Press. 